\title{
A FORMAÇÃO EM PEDAGOGIA NA FACULDADE DE EDUCAÇÃO - UFC, ENTRE 1987 A 2007
}

Flávio Muniz Chaves ${ }^{1}$

Francisco Ari De Andrade ${ }^{2}$

\section{INTRODUÇÃO}

O presente artigo foi tecido a partir de dados integrantes de uma pesquisa de tese de doutoramento em Educação, na Universidade Federal do Ceará. Este texto põe em relevo a formação em Pedagogia no Ceará, nas versões dos Projetos Pedagógicos do Curso - PPC, no interstício de 1987 a 2000. Nesse estudo procuramos refletir, principalmente, a relação das versões dos Projetos Pedagógicos de Curso (PPC) no perfil de formação do profissional em Pedagogia, conforme as diretrizes do Ministério de Educação - MEC.

No intervalo de duas décadas, na passagem do século XX para o século XXI, o Curso de Pedagogia da Faculdade de Educação da Universidade Federal do Ceará passou por três verões de Projeto do Curso, a saber: a versão de 1987, a aversão e 1990 e a versão de 2007, sendo esta última em atendimento às Diretrizes Curriculares do Curso de Pedagogia no Brasil.

Nosso intuito nesse estudo é apresentar pontos de congruências entre as orientações trazidas por cada versão do Projeto do Curso e a realidade complexa de uma sociedade plural e democrática, com seus desafios educacionais latentes. Por meio desse debate buscamos compreender a incorporação das mudanças ocorridas na sociedade brasileira a influenciar a formação docente, em particular, em Pedagogia. Nesse sentido, os projetos pedagógicos são elaborados e modificados para melhor atender as demandas da sociedade ao definir o perfil do profissional que a universidade se propõe a formar, conforme as diretrizes orientadas pelo MEC para o curso Pedagogia.

O desenvolvimento do estudo foi pautado em três etapas. Na primeira, de cunho bibliográfico, fez-se uma incursão sobre os principais teóricos da educação brasileira que discutem a questão da formação docente, em particular em Pedagogia, e o papel do Projeto Pedagógico na orientação da formação superior. Na segunda etapa, analisaram-se as versões dos projetos de curso, procurando-se

\footnotetext{
${ }^{1}$ Doutor em Educação pela Universidade Federal do Ceará.

2 Professor Associado 1 do Departamento de Fundamentos da Educação, na Faculdade de Educação da Universidade Federal do Ceará.
} 
entender a orientação formativa. Na terceira, apresentaram-se recortes de entrevistas com aqueles que exerceram a função de coordenador(a) do curso durante o período de elaboração de tais reformulações, que atendiam as demandas da época.

Consideramos que tal estudo seja oportuno para entender a formação em Pedagogia, constantemente adequada às demandas de uma sociedade complexa, plural e democrática.

\section{AS MUDANÇAS NA FACULDADE DE EDUCAÇÃO ENTRE OS ANOS DE 1980 DO SÉCULO XX ATÉ O INÍCIO DO SÉCULO XXI}

Os primeiros anos da década de 1980 foram muito conflitantes e geraram inúmeros debates internos sobre o caminhar do Departamento de Educação no Centro de Estudos Sociais Aplicados (CESA) e na própria universidade. Em 1984, outra mudança institucional: com o desaparecimento do CESA, o Departamento de Educação retorna com a estrutura da Faculdade de Educação (Fernandes, 2014). Fazia-se necessário, dentro do contexto histórico, que o departamento voltasse a ser faculdade. O momento era de extrema agitação política e cultural. Até 1985, o país ainda estava sob o domínio do governo militar, apesar de a partir de 1979 os militares iniciaram o que ficou conhecido como "transição democrática".

Na FACED, essa discussão se iniciou no ano de 1981, após o seminário Educação e Debate. Em 1983 os docentes da Pedagogia se reúnem para debater sobre o Processo de Reformulação Curricular, tendo como base os documentos brasileiros (Fernandes, 2014).

Em 1985 foram aplicados questionários com discentes e docentes, para tentar compreender quais eram os problemas mais graves da formação em Pedagogia e qual era o perfil do/da profissional que era formado/a por essa instituição (Fernandes, 2014). Após a coleta dos resultados, foi realizado um seminário para expor os resultados obtidos nas respostas dos questionários desfechos e iniciar o desenvolvimento de uma proposta de reformulação curricular para o curso de Pedagogia da FACED. Quem colaborou com essa discussão de reformulação curricular foram os professores Jamil Cury e Miguel Arroyo (Fernandes, 2014). Em 1986 foi redigido um preâmbulo da concepção de currículo. E o que constava nesse preâmbulo?

[...] a fundamentação e os objetivos que deveriam servir de base aos debates verificados em todos os colegiados, tais como: coordenação de curso, unidades curriculares, departamentos, assembleias, grupos de estudo e centro acadêmico. Em todos esses níveis de discussão estavam presentes alunos e professores (FERNANDES, 2014, p. 151) 
O documento começava a se delinear sem perder de vista o aspecto democrático do debate, destinando-se a todos os atores sociais da instituição, os quais participaram, debateram e sugeriram mudanças para o que consideravam, na época, as melhores propostas curriculares para o curso de Pedagogia. Após essa etapa, foi preciso pensar sobre como seria criada uma organização por áreas de conhecimento e como cada uma dessas áreas deveriam cooperar para a formação do pedagogo baseado no seu fundamento. Todo esse trabalho resultou no documento de propostas curriculares para uma nova realidade do curso de Pedagogia. As habilitações permaneceram, mas não aquelas voltadas para a formação do especialista em educação, e sim, habilitações que aprofundavam o conhecimento em Pedagogia nas áreas mais carentes da educação local, regional e nacional. Esse novo currículo foi adotado no segundo semestre do ano de 1987, tendo sido aprovado em todas as instâncias deliberativas da Faculdade, da Universidade e do Conselho Federal de Educação. Nascia o primeiro Projeto Pedagógico da FACED.

No mesmo ano, o projeto pedagógico aprovado foi sendo implantado gradativamente, delimitando o curso em quatro (4) anos O novo projeto pedagógico foi sendo avaliado durante a sua implantação, e a primeira escolha foi pela escola pública e gratuita (Fernandes, 2014).

E como seria a formação do pedagogo com essa mudança no projeto pedagógico?

[...] deverá superar a fragmentação do pensar, ser e fazer na educação e a hierarquização do trabalho pedagógico, atuando basicamente, como docente nas áreas de pré-escolar, séries iniciais do primeiro grau, curso pedagógico de $2^{\circ}$ grau, educação de adultos e educação especial. (FERNANDES apud DOCUMENTO DE PROPOSTA CURRICULAR DO CURSO DE PEDAGOGIA DA UFC, 2014, folha 3,).

O novo currículo implantado no curso de Pedagogia tinha essa linha de pensamento para a sua formação. Se o pensar, o ser e o fazer foram divididos, precisaram ser resgatados para recompor a identidade docente da Pedagogia. Se na década de 1970 era o especialista no professor, agora era o docente se reencontrando com o seu ser na educação, pois a docência é o sustentáculo de toda a educação. Fica claro que o perfil profissional em Pedagogia continua amplo: docente na pré-escola, nas séries iniciais, a formação pedagógica no segundo grau, educação de adultos (atualmente conhecida como EJA) e educação especial. A formação não visava mais o especialista tecnicista burocrático da administração, orientação e supervisão educacional. Continuaram a ter essas habilitações técnicas, explicaremos mais adiante o que aconteceu com essas habilitações. No entanto, o foco voltou-se para a sala de aula e suas problemáticas.

A teoria e a prática também estavam presentes nessa proposta curricular, mas continuava da mesma forma que no período militar: teoria no início e prática no final da graduação. Sobre essa 
questão temos a seguinte informação: "podemos concluir que houve uma mudança na perspectiva do curso, principalmente, em nível teórico, levando a algumas experiências novas da prática" (Fernandes, 2014, p. 172). Aquela perspectiva generalista do pedagogo teórico acabou. Essa mudança veio para poder ampliar o horizonte da formação visando preparar esse docente para uma realidade por meio da qual precisa de segurança teórica para poder aplicar no cotidiano do espeço escolar. Muitos professores precisaram continuar a pós-graduação devido a cobrança de alunos pela falta de fundamento teórico nas suas concepções políticas ou pelo excesso de aulas tradicionais.

E por qual motivo isso aconteceu na FACED? "O grande vazio teórico do curso de Pedagogia iniciou-se no fim da década de 1970 e desembocou na década de 1980" (Fernandes, p. 173, 2014). A Pedagogia da UFC durante a década de 1980 e antes dessa reformulação no seu projeto pedagógico, era muito carente de uma teoria pedagógica. Como o curso tinha uma abordagem tecnicista da educação, esvaziou a teoria para somente preparar o burocrata da educação. Ocorreu essa reflexão dentro da graduação, e as mudanças foram inevitáveis. Mas ocorreram resistências por parte de alguns docentes que não tinham se adaptado ao novo modelo docente que surgia: o professor globalista ou crítico (Fernandes, 2014).

Depois desse momento turbulento, porém muito produtivo, a FACED entra nos anos de 1990. Ocorrem dois fatos importantes na história dessa instituição: a criação do curso noturno e o fim das habilitações dos especialistas. Em 1990 foi enviada uma proposta de criação do curso noturno de Pedagogia. Os maiores beneficiados por essa criação seriam os trabalhadores, que laboravam de dia e tinham a oportunidade de cursar uma graduação à noite. Gerou-se um debate sobre a criação desse curso noturno após a implantação da nova proposta curricular de 1987. As principais indagações para essa criação foram as seguintes: a democratização do ensino, tendo em vista que a universidade ficava fechada no período noturno; a qualidade do ensino e os aspectos legais (Proposta Curricular do Ensino Noturno do Curso de Pedagogia, 1990).

Após essas reflexões iniciais no documento, aparece a ideia inicial de formação em Pedagogia durante o curso noturno. Conforme a Proposta Curricular do Ensino Noturno (1990), este seria o perfil do pedagogo a ser formado:

[...] um educador que compreenda a sociedade e a educação brasileira, sobretudo a escola pública, realidade concreta inserida num contexto histórico e social específico. E ainda um educador capaz de participar efetivamente do processo de criação de uma escola brasileira democrática, que responda aos interesses da maioria da população. Nessa ótica, o pedagogo necessita ser, um educador (PROJETO PEDAGÓGICO, p. 7-8). 
Essa perspectiva formativa em Pedagogia necessitava de um profissional comprometido com a educação do seu país, compreendendo o contexto histórico e social. A formação era voltada exclusivamente para a escola pública, tendo sua formação como uma garantia democrática. Esse profissional da educação nascia educador, provavelmente devido ao amplo leque de espaços educativos que a Pedagogia proporciona no seu campo de atuação. Foi uma visão de futuro e de oportunidade que surgiu com a criação desse curso noturno.

No tocante ao currículo, a graduação tinha um currículo básico de 200 créditos, sendo cursado, no mínimo, em seis (6) e, no máximo, em nove (9) anos, uma vez que o curso noturno se destinava a estudantes que trabalhavam durante o dia, permitindo, dessa forma, a conclusão do curso no período citado. As disciplinas foram divididas da seguinte maneira:

1 - disciplinas do ciclo básico ou $1^{\circ}$ ciclo;

2 - disciplinas do ciclo profissional, estas subdivididas em:

a - disciplinas obrigatórias, comum a todos os alunos;

b - disciplinas optativas do núcleo de aprofundamento que visam ao pedagogo aprofundar - se na docência de clientelas específicas (adultos, pré-escolar, educação especial);

c - disciplinas optativas complementares que visam o enriquecimento da formação (PROPOSTA CURRICULAR DO ENSINO NOTURNO DO CURSO DE PEDAGOGIA, 1990, p. 11 - 12).

Cada semestre tinha quinze (15) semanas para serem cursadas. As aulas iniciavam as 18h30 min e terminavam as 22h (Proposta Curricular do Ensino Noturno do Curso de Pedagogia, 1990). Dependendo dos créditos cursados pelos discentes, as sextas-feiras eram para estudo na faculdade. No dia 11 de dezembro de 1990, após ser aprovado no CEPE da UFC, a pró-reitora de graduação Joseneide Franklin Cavalcante, encaminhou o parecer favorável à proposta curricular do curso noturno da FACED para apreciação da reitoria. No dia 18 de dezembro de 1990, sai a Resolução N $^{\circ}$ 26 do CEPE, aprovando a estrutura curricular da Pedagogia noturna, assinada pelo reitor Raimundo Hélio Leite.

Após essa breve apresentação sobre a criação do curso noturno da Pedagogia, ainda é preciso terminar um assunto polêmico que estava gerando discussão e debates na FACED: a formação do especialista. Mesmo com todas as mudanças iniciadas na década de 1980, essa formação continuava gerando discussões. O corpo discente e docente concluiu que a docência era a essência dessa graduação e não o especialista em educação. Durante um encontro na Faced, entre os dias dez (10) e 
onze (11) de maio de 1990, o Departamento de Teoria e Prática redigiu um documento intitulado "Repensando as Habilitações" (Fernandes, 2014). Era justamente esse departamento o responsável por oferecer essas disciplinas das habilitações para as especialidades. O departamento pedia a extinção dessas habilitações imediatamente.

O documento foi aprovado, porém, outros encontros foram feitos para aprofundar o debate; estes foram organizados, principalmente, pelo Centro Acadêmico Paulo Freire (CAPF). Após várias reuniões, surgiram três propostas:

1. Extinção das habilitações educacionais, assegurando o direito somente aqueles alunos que já estão cursando as habilitações (Proposta do Departamento de Teoria e Prática);

2. Extinção imediata das habilitações educacionais, resguardando o direito de cursá-las aqueles alunos regidos pelo currículo antigo (proposta apresentada pela profa. Laura Maria de Sousa Vieira e referendada pela representação estudantil);

3. Transformação da formação dos especialistas em educação para nível de pós-graduação (proposta da profa. Maria Luísa Barbosa Chaves) (FERNANDES,2014, p. 182).

Venceu a proposta de número um (1), mesmo tendo sua legalidade questionada. Por meio desta, os estudantes exigiram que continuassem sendo oferecidas as disciplinas para os especialistas da educação para os alunos pertencentes ao currículo antigo. Outra votação foi feita e venceu a extinção das habilitações para formar o especialista em educação. Os alunos do currículo antigo só tinham até três anos para cursarem essas disciplinas.

No ano de 2006 é que a FACED iria modificar o seu projeto pedagógico, já que ele se mantinha inalterado desde 1987. As áreas de aprofundamento desapareceram e deram lugar à formação mais ampla, devido aos novos espaços que o curso de Pedagogia tinha conquistado. Com as DCNCP, em 2006, exigindo a mudança no PPC, durante o ano 2007 ocorreu a discussão e a finalização do Projeto Pedagógico do século XXI.

\section{A IMPORTÂNCIA DO PLANO PEDAGÓGICO DE CURSO/PROJETO PEDAGÓGICO NA FORMAÇÃO EM PEDAGOGIA}

O PPC/PP não deve ser uma "carta de intenções" no qual não é perceptível os avanços no cotidiano escolar/acadêmico. Está contido neste documento todo um processo pedagógico que precisa ser vivenciado, posto em prática e refletido a luz dos pares, destacando-se, principalmente, os seguintes itens: perceber as relações professor-aluno, entre os pares, uma crítica construtiva à prática pedagógica, as mudanças que ocorrem na cidade e no país, entre muitas outras situações. 
Para além de todos esses aspectos, o PP é um documento formativo. Toda a formação de um estudante está contida nesse plano. A leitura do mesmo não pode ser superficial, nem deixada em segundo plano. Todos os componentes do corpo da instituição escolar/universitária precisam ter contato e refletir sobre o seu papel na participação e efetivação desse projeto pedagógico. Se há garantia de que o trabalho em conjunto em prol do compromisso de uma aplicabilidade do que está descrito no plano, o salto qualitativo durante toda a formação do discente poderá ser excepcional.

Aos participantes que contribuíram para a elaboração do plano exigia-se atuação de forma respeitosa, coerente, compromissada, com responsabilidade, e que a intencionalidade fosse a mais pedagógica possível. Dessa forma, haveria uma aproximação maior dos alunos, fazendo com que a relação docente-discente e ensino-aprendizagem melhorasse, e as mudanças propostas pudessem ter um significado maior em relação ao conteúdo ministrado, em relação as mudanças sobre o aprendizado dos estudantes e uma atualização dos processos formativos e tecnológicos nos quais a sociedade está inserida, dentro daquele contexto histórico. Esse documento não pode ficar esquecido em uma gaveta na diretoria ou na coordenação da escola/universidade. Assim como a legislação educacional tem uma função social, o PP também tem um objetivo a ser alcançado. Uma sugestão seria que a gestão/direção fizesse avaliações sobre esse documento e relembrasse aos que participaram e aos que não participaram, que a reflexão sobre o documento precisa ser efetivada.

O destaque a esses aspectos foi necessário para que se possa refletir sobre a importância do debate político, reflexão sobre o PP dos assuntos relativos sob o efeito da educação, a formação do educando, a epistemologia, as perspectivas metodológicas, dentre outros assuntos significativos para essa temática. E como se aplicaria o PP?

- A proposta do que quer ajudar a alcançar como resultado social e de como quer ser (e precisa ser) para isso;

- A avaliação de até que ponto está contribuindo para o que quer alcançar e de até que ponto age como propôs em seu ideal;

- A proposta de ações, comportamentos e atitudes [...] para um determinado período de tempo, a fim de tornar - se mais parecida com o ideal que escolheu (GANDIN, 1999, p. 18).

Temos os seguintes aspectos: um ideal a ser seguido (visão de ser humano), uma meta a ser alcançada (objetivos), como se atingir essa meta (metodologia), uma avaliação mais qualitativa (avaliar todo o processo), o tempo que foi determinado para as propostas sugeridas pelas discussões em torno do Projeto Pedagógico são possíveis para alcançar o ideal desejado.

E por que o PP pode ser tornar um documento engavetado ou esquecido? Conforme Veiga (2012): “a falta de clareza na compreensão da ideia de projeto é o que propicia sua implantação de 
forma burocrática e fragmentada. O projeto é elaborado e executado apenas para cumprir orientações provenientes do poder central e da legislação" (p. 18). O que ocorre, na maioria dos casos, é que esse documento fica guardado e esquecido, sem ser utilizado pelos personagens que o redigiram. Acaba se tornando uma obrigação e não uma perspectiva formativa. Em relação à graduação em Pedagogia, essa reflexão é importante devido as mudanças na legislação educacional que ocorrem constantemente no país. Para além das leis nacionais, temos as leis estaduais, municipais, pareceres ou decretos. Essa constante mudança está intrinsicamente ligada a um mundo que a partir dos anos 2000 exigem novas formas de ensinar, formar e profissionalizar os universitários.

Nessa perspectiva, mudar os PP é adaptar ou readaptar uma realidade que urge com necessidades e novos paradigmas profissionais que se transformam em uma velocidade assustadora. $\mathrm{O}$ curso de Pedagogia, numa perspectiva do século XX, tinha uma demanda curricular e um perfil profissional que, na época, era considerado necessário.

Essas mudanças precisam resultar em um trabalho árduo, que é a reflexão e ação de mudar os modelos existentes de perfil profissional e tentar melhorar a formação em Pedagogia para uma realidade cada vez mais dinâmica. Essas mudanças se iniciam no Projeto Pedagógico e perpassam por toda a graduação e, no final do processo, vai diplomar aquele discente que cursou, durante quatro (4) ou cinco (5) anos, a graduação de Pedagogia e precisa estar preparado para lidar com uma sala de aula heterogênea, com um sistema educativo público ou privado e com as exigências do mundo moderno.

Por tais fatos apresentados, se faz importante valorizar o processo de mudança do PP e a reflexão sobre a formação em Pedagogia, para não se ter um direcionamento pessoal no momento de decisão sobre quem estamos formando e estregando para os espaços escolares e não escolares, a educação formal, não formal e informal. Não é um PP de curso de Pedagogia: "Ele é parte de um projeto institucional, que é parte de uma universidade, que é parte de um sistema de educação, que é parte de um projeto de sociedade" (VEIGA, 2012, p. 17).

E sobre tudo o que se redigiu anteriormente, é preciso uma forma de conexão entre esses eixos:

A situação real e a desejada, reduzindo a distância entre o discurso e a prática;

Os diferentes atos operacionais e administrativos, conceituais e pedagógicos; $\mathrm{O}$ projeto pedagógico institucional e o projeto acadêmico (de curso) (VEIGA, 2012, p. 21).

Sobre a relação da universidade com os cursos de graduação e o PPC, Veiga (2012) reflete sobre essa tríade 
[...] o projeto político pedagógico é mais do que uma formalidade instituída: é uma reflexão sobre a educação superior, sobre o ensino, a pesquisa e a extensão, a produção e a socialização dos conhecimentos, sobre o aluno e o professor e a prática pedagógica que se realiza na universidade (p. 25).

A dimensão do PPC, como está na citação, é para além do que se imaginava na universidade: é sobre os fazeres, as práticas pedagógicas e as relações de conhecimento no interior dessa instituição. Por isso, esse documento legal é a coluna de sustentação da universidade e de cada curso de graduação. E quais seriam as outras dimensões de um projeto pedagógico?

Integrar ações dispersas de ensino, pesquisa e extensão;

Criar sinergias no sentido de buscar soluções alternativas para diferentes momentos do trabalho acadêmico - administrativo;

Desenvolver o sentimento de pertença;

Mobilizar os protagonistas para a explicitação de objetivos comuns, definindo o norte das ações a serem desencadeadas;

Fortalecer a construção de uma coerência comum, mas indispensável, para que a ação coletiva produza efeitos (VEIGA, 2012, p. 54).

As dimensões apresentadas na citação demonstram o quanto se faz necessário dialogar com todas as partes integrantes da universidade (no caso macro) e nos cursos de graduação (no caso micro). Todas as áreas de pesquisa precisam estar em uma permanente comunicação para que se possa melhorar durante o antes e o durante da implantação do projeto pedagógico. Nesse caso específico, essas soluções não são somente de ordem pedagógica, há outras demandas institucionais que impedem algumas soluções. Por isso que a autora, na citação, versa sobre esses momentos acadêmicos e administrativos.

Quando a comunidade acadêmica vai definir/redefinir um PP, é preciso que esteja muito claro quais são os objetivos que irão trilhar. É a partir deles que poderão ser traçadas novas linhas de práxis pedagógica para melhorar ou modificar tudo aquilo que está no antigo projeto pedagógico e, dessa forma, ter um norte para o futuro na formação em Pedagogia. A partir desse ponto, vão sendo estimuladas as ações ligadas intrinsicamente aos objetivos. Todas essas dimensões finalizam com uma atividade em comum, por meio da qual os participantes desse processo vão aplicando no cotidiano universitário da graduação esse PP e percebendo as mudanças que dele virão. Por isso o PP é um documento e projeto institucional.

E quais são os componentes necessários e fundamentais para a elaboração do PPC? Conforme Veiga (2012), um olhar contemporâneo sobre as mudanças no mundo, a função educativa refletida no ambiente social e tecnológico, uma escolha por um paradigma que inclua as pessoas e uma 
formação mais voltada para a criticidade e alteração do cotidiano desse profissional que será formado tendo como base as reflexões surgidas ao longo do processo de mudança no projeto pedagógico. É importante mencionar um fator extremamente importante para essa discussão: a intencionalidade pedagógica do PP. Ao longo de tal processo de construção, é necessário se pensar quem está sendo formado/a, qual profissional a universidade/faculdade está concebendo, devolvendo para a sociedade e para o mercado de trabalho.

\section{NARRATIVAS DE SUJETIOS QUE COLABORARAM NA ELABORAÇÃO DAS VERSÕES DOS PROJETOS DE CURSO}

Os sujeitos da pesquisa são ex-coordenadoras do curso de Pedagogia da FACED/UFC e estiveram à frente do processo de discussão da Proposta de Reformulação do Currículo de Pedagogia (PRCP) antes de ser denominado de Projeto Pedagógico, atual Plano Pedagógico de Curso. São personagens importantes que estiveram presentes em todas as etapas dessa mudança de paradigmas no curso de Pedagogia. Esses relatos são oportunos para que se possa conhecer e refletir sobre como foi preparado todo o processo, desde diálogos, sobre o que foi abordado nas discussões, os personagens que compuseram as reuniões, como se delineia o projeto pedagógico e como o perfil profissional do curso de Pedagogia foi pensando e colocado em pauta no currículo.

A primeira pergunta foi: Qual era o contexto da época em que ocorreu a mudança no antigo Projeto Político Pedagógico (PPP), atual Plano Pedagógico de Curso? Quais eram as prioridades na formação do pedagogo? As respostas dão conta das seguintes elucidações:

PP80 - A década de 1980, vivida pela Faculdade de Educação, a princípio funcionando como Departamento de Educação da UFC ligado ao Centro de Estudos Sociais Aplicados (CESA), fora acometida de muita turbulência causada por:

- Reflexo do clima de abertura política do país, levando as pessoas a terem posicionamentos mais transparentes (a dimensão do Projeto do Mestrado em Educação se deu num clima político caloroso) - as posições fechadas de grupos mais reacionários à mudança por um lado, e de grupos progressistas radicais que, pelo respaldo teórico que possuíam, tomavam postura de "iluminados" da faculdade;

- O clima de insegurança emocional decorrente dos concursos internos de professores, provocando atritos e insatisfação entre os colegas

PP90 - Estávamos numa época em que se redimensionava a Pedagogia - ao invés de ênfase em habilitações (orientação, supervisão, direção), o enfoque era na docência: as habilitações, principalmente a supervisão e a direção seriam componentes da gestão pedagógica, cuja base continuaria sendo a docência (mas elas - supervisão e direção - não seriam "vitalícia", mas decorrentes de "rodízio" entre professores (pela via da eleição direta e participativa entre professores, alunos e pais/responsáveis.

PP2007 - A RESOLUÇÃO CNE/CP Nº 1, DE 15 DE MAIO DE 2006, que institui Diretrizes Curriculares Nacionais para o Curso de Graduação em Pedagogia, licenciatura, estabelece no Art. $2^{\circ}$ que As Diretrizes Curriculares para o curso de Pedagogia aplicam-se à formação inicial 
para o exercício da docência na Educação Infantil e nos anos iniciais do Ensino Fundamental, nos cursos de Ensino Médio, na modalidade Normal, e em cursos de Educação Profissional na área de serviços e apoio escolar, bem como em outras áreas nas quais sejam previstos conhecimentos pedagógicos.

A segunda pergunta do questionário inquiriu sobre: Como ocorreu o processo de mudança e reestruturação do PPC do curso de Pedagogia? Quais foram os atores sociais que participaram dessas reuniões? Quais foram as temáticas mais debatidas? Quais temáticas, no seu entendimento, negligenciadas?

PP80 - 1. Apanhado de todos os documentos elaborados sobre esta questão (dossiê). 2. Questionários aplicados aos alunos e professores sobre os pontos de estrangulamento do curso em vigência e de delineamento do profissional que se pretendia formar. Os resultados foram apresentados em painel, num seminário inicial de discussão do novo currículo (1985).

3. Versão preliminar da Proposta Curricular (1986) - apresentação de fundamentos e objetivos - amplamente discutidos por todos os colegiados, com participação de professores e alunos. As deliberações finais sempre aprovadas em Assembleias Gerais.

4 Envio do Documento final para aprovação em todos os departamentos; ao Conselho Departamental e, finalmente ao Conselho Universitário (1987.2) - Conselho Federal de Educação.

Atores sociais:

- Toda a comunidade da Faculdade (alunos/professores).

- Ausência dos funcionários.

Temáticas mais debatidas:

- Habilitações educacionais.

Temáticas negligenciadas:

-Estrutura da Faculdade frente ao novo currículo (relação de poder) - tema “quase proibido".

PP90 - À época da primeira mudança no currículo, sob o enfoque da docência, as temáticas mais discutidas eram exatamente aquelas que davam a sustentação para o ensino (na educação infantil e nas séries/nos anos iniciais do ensino fundamental), associadas à não retirada ou diminuição de carga horária de determinadas disciplinas, como Estatística, Psicologia. As demais áreas/modalidades de atuação do pedagogo (notadamente educação de jovens e adultos, educação especial e inclusiva) não foram tão discutidas quanto mereciam... A visão de direção, superando a noção de administração/gerenciamento (mais burocrático), e dando um caráter mais amplo e necessário, no sentido de gestão da escola, dos currículos e das disciplinas/matérias (que o curso de Pedagogia enfocava) também mereciam uma reflexão maior.

PP2007 - Quais foram os atores sociais que participavam dessas reuniões?

Colegiado: chefe dos departamentos, representante dos docentes por departamento, representação estudantil.

Quais foram as temáticas mais debatidas?

Formação para docência na modalidade polivalente, para a educação infantil

A penúltima pergunta do questionário procurou entender, nessas respectivas mudanças, o que foi mais priorizado na formação, a teoria ou a prática? Foram criadas estratégias para verificar como essa articulação proposta foi implementada pelos professores nas disciplinas? 
PP80 - No contexto geral da vivência do novo currículo, temos sentido que em certos aspectos houve avanço, mas em outros ainda estávamos engatinhando. Na nossa percepção, avançamos com as experiências de:

- Projetos Especiais- principalmente pela "busca de construção do saber coletivo";

- Integração do BÁSICO ao Curso de pedagogia: os alunos sentiram-se mais envolvidos ao curso e à Universidade desde o $1^{\circ}$ semestre, principalmente, por causa do "Seminário ao Curso de Pedagogia" realizado na primeira semana de aula. Esta experiência serviu de exemplo para outros cursos da Universidade e para uma possível mudança estrutural nesse aspecto;

- Estágio integrado de Pedagogia e Licenciaturas numa mesma Escola - Apesar da reformulação curricular não ter atingido o semestre de estágio, o clima de mudança levou os professores a elaborarem um projeto, integrando os alunos do currículo antigo, em caráter experimental, já traziam efeitos positivos;

- Ofertas de disciplinas optativas do currículo novo, para alunos do currículo antigo. Isto é um resultado da compreensão mais abrangente de currículo, não limitando a um grupo ou a determinadas atividades, mas englobando toda a vivência da instituição;

PP90 - Integração entre teoria e prática. A tentativa, ou a estratégia, foi a criação de disciplinas intituladas de Projeto Especial (do I ao VI), que, em cada semestre, procurava fazer a integração ente as disciplinas concomitantes.

PP07 - No PPC as duas vertentes: teoria e prática se complementavam, no entanto, nas práticas educativas e pedagógicas a parte prática eram incipientes, em face da prioridade aos aspectos teóricos das disciplinas.

Embora houvesse uma coordenação de avaliação institucional que tinha com atribuições dinamizar a avaliação de programa e projetos naquela época não foram realizadas as avaliações formativas dos projetos pedagógicos dos cursos de graduação pela Pró-Reitoria de Graduação, pela Faced, pelo colegiado da coordenação do curso. Não houve qualquer evento para analisar ou avaliar a implementação e implantação do processo formativo do PPC.

E, finalmente, a última pergunta desse questionário procura saber o perfil do profissional pedagogo antes e depois das mudanças nos PPCs? Eis as colocações:

PP80 - Uma formação globalizante do educador de modo que ele possa exercer qualquer função dentro da escola, com competência, quando escolhido pela comunidade escolar, necessitando, para isto, que se aumente o número de créditos da disciplina: "Organização social do trabalho escolar", já constante do currículo novo do curso de pedagogia da UFC, pois através dela se daria toda uma visão das funções da escola, de forma dinâmica e integrada, e condições para o seu exercício. A faculdade de Educação da UFC vivenciou tanto a formação do generalista de cunho essencialmente humanista, como a formação do especialista influenciado pela linha tecnicista.

PP90 - Antes era o profissional habilitado em docência no Ensino Médio (curso Pedagógico, de nível médio), supervisão, orientação e ou direção. Posteriormente, passou a ser docência na Educação Infantil e nas séries/anos iniciais do Ensino Fundamental, gestão, educação popular (jovens e adultos), educação especial e docência no Ensino Médio (curso Pedagógico de nível médio), seguindo orientação da LDB atual.

PP07 - O profissional em pedagogia tinha uma formação básica na vertente polivalente com opções de aprofundamento em arte e educação, educação de jovens e adultos, educação infantil e.......

Atualmente, o PPC promove uma formação polivalente em educação infantil e ensino fundamental I

\section{Considerações Finais}

A formação em Pedagogia precisa se modificar sempre para se adequar a uma nova realidade educativa, que necessita mudar para colaborar na educação de qualidade. Isso se dá ao longo de quatro 
ou cinco anos, dependendo se a opção for pelo período diurno ou noturno. Essa mudança acontece, principalmente, por conta da carga horária necessária para essa Graduação. Modificar esse importante documento, o PPC, não é simplesmente participar de reuniões ou compreender que o docente é dono dessa ou daquela disciplina.

Conclui-se que a formação em Pedagogia se modifica para se adequar às demandas da realidade educativa. Modificar o PPC é refletir a formação à luz das teorias pedagógicas. É um esforço para entregar à sociedade os profissionais da educação responsáveis pela base da educação nacional, porque precisam compreender a relação teoria e prática no oficio docente.

Toda e qualquer modificação precisa ser refletida à luz das teorias pedagógicas. É um esforço para entregar à sociedade os profissionais da educação que são responsáveis pela base da educação nacional, que é a Educação Infantil e o Ensino Fundamental 1. Eles precisam compreender a relação teoria e prática para poderem trabalhar os conteúdos elementares e necessários para as outras etapas da educação básica brasileira. Se os responsáveis, os docentes do curso de Pedagogia, não compreenderem a intencionalidade pedagógica e tomarem para si essa mudança como primordial, o PPC será somente uma carta de intenções.

O profissional da educação em Pedagogia está contido dentro deste documento, que todos os professores formadores da FACED deveriam ler e adaptar às suas práticas pedagógicas nas suas aulas, pensando no profissional docente que estão entregando à sociedade e às escolas públicas do Estado do Ceará. Refletir sobre a formação em Pedagogia é pensar em um discente que está sendo moldado para encarar a docência como uma profissão, não como um mero passatempo. Se teoria e prática caminham juntas, formação docente e PPC também caminham.

\section{REFERENCIAS}

BRZEZINSKI, Iria. A formação do professor para o início da escolarização/Iria Brzezinski - Goiânia: ed. UCG/SE. 1987. $238 \mathrm{p}$.

BRZEZINSKI, Iria. Formação de professores: um desafio/ Iria Brzezinski (Organizadora). - Goiânia: UCG, 1996.248 p.

BRZEZINSKI, Iria. Pedagogia, pedagogos e formação de professores/Iria Brzezinski. - 9. Ed. - Campinas, SP: Papirus, 2012.

FERNANDES, Maria Estrêla Araújo. Gramsci e a formação de educadores: revendo a teoria gramscista para melhor entender a proposta curricular do curso de Pedagogia da UFC. Educação em Debate, n.21/22m o,31-46, jan./dez. 1991.

O curso de Pedagogia da UFC: uma resenha histórica (1963 - 1990). Fortaleza: Edições UFC, 2014. 
Faculdade de Educação. Proposta Curricular do Ensino Noturno do Curso de Pedagogia, nov. 1990.

. Proposta Curricular de reformulação do curso de Pedagogia. Fortaleza, 1986.

Projeto Pedagógico do curso de Pedagogia. Fortaleza, 2007.

GANDIN, Danilo; GANDIN, Luis Armando. Temas para um projeto político-pedagógico. Petrópolis, RJ: Vozes, 1999. LIBÃNEO, José Carlos. Educação escolar: políticas, estruturas e organização/José Carlos Libâneo, João Ferreira de Oliveira, Mirza Seabra Toschi - 9. Ed. - São Paulo: Cortez, 2010.

LIBÂNEO, José Carlos. Pedagogia e pedagogos, para quê? /José Carlos Libâneo. - 8. Ed. - São Paulo, Cortez, 2005.

TARDIF, Maurice; Claude L. O ofício de professor: história, perspectivas e desafios internacionais/Maurice Tardif, Claude Lessard: tradução de Lucy Magalhães. 4. ed. - Petrópolis, RJ: Vozes, 2011.

VEIGA, Ilma Passos Alencastro. Educação básica: projeto político-pedagógico; Educação Superior; Projeto Político Pedagógico. 6. ed. Campinas, SP: Papirus, 2012.

ZAIDAN, Samira. Reformas educacionais e formação de professores no Brasil in Reformas educacionais na América Latina e os trabalhadores docentes / Dalila Andrade Oliveira. - Belo Horizonte: Autêntica, 2003, p. 143 - 148. 


\section{A FORMAÇÃO EM PEDAGOGIA NA FACULDADE DE EDUCAÇÃO - UFC, ENTRE 1987 A 2007.}

RESUMO: O presente artigo é parte integrante da tese de doutoramento em Educação na Universidade Federal do Ceará, intitulada "A formação docente nos percursos e itinerários dos projetos pedagógicos do curso de pedagogia da faculdade de educação - FACED/UFC, entre 1987 e 2007". Para onde apontou a formação nas diversas versões dos PPC's, conforme as exigências e adequações trazidas pelas reformas curriculares do Ministério da Educação - MEC, para os cursos de Pedagogia? O Projeto Pedagógico do Curso é considerado o instrumento fundamental de orientação da formação profissional superior. Admite-se que tal estudo seja oportuno para entender a formação em Pedagogia constantemente adequada às demandas de uma sociedade complexa, plural e democrática.

Palavras-chave: formação; educação; docência; projeto; pedagogia

\section{TRAINING IN PEDAGOGY AT THE SCHOOL OF EDUCATION - UFC, BETWEEN 1987 AND 2007}

ABSTRACT: This article is an integral part of the PhD thesis in Education at the Federal University of Ceará, entitled "Teacher training in the pathways and itineraries of the pedagogical projects of the Faculty of Education - FACED / UFC, between 1987 and 2007Where pointed the formation in the various versions of the PPC's, according to the requirements and adjustments brought by the curricular reforms of the Ministry of Education? Education - MEC, for Pedagogy courses? The Pedagogical Project of the Course is considered the fundamental instrument of orientation of the superior professional formation. It is admitted that such study is opportune to understand the formation in Pedagogy constantly adequate to the demands of a complex, plural and democratic society.

Keywords: formation - education - teaching - project - pedagogy

\section{ENTRENAMIENTO EN PEDAGOGÍA EN LA ESCUELA DE EDUCACION - UFC, ENTRE 1987 Y 2007.}

RESUMEN: Este artículo es una parte integral de la tesis doctoral en Educación de la Universidad Federal de Ceará, titulada "Capacitación docente en las rutas e itinerarios de los proyectos pedagógicos de la Facultad de Educación - FACED / UFC, entre 1987 y 2007". Dónde apuntó la formación en las diversas versiones de los PPC, de acuerdo con los requisitos y ajustes traídos por las reformas curriculares del Ministerio de Educación? Educación - MEC, para cursos de pedagogía? El Proyecto Pedagógico del Curso se considera el instrumento fundamental de orientación de la formación profesional superior. Se admite que dicho estudio es oportuno para comprender la formación en pedagogía constantemente adecuada a las demandas de una sociedad compleja, plural y democrática.

Palabras clave: formación - educación - enseñanza - proyecto - pedagogía

Submetido em Julho de 2019

Aprovado em Novembro de 2019 